Research Paper

\title{
High Producing Tumor Necrosis Factor Alpha Gene Alleles in Protection against Severe Manifestations of Dengue
}

\author{
Sing-Sin Sam¹, Boon-Teong Teoh¹, Karuthan Chinna², Sazaly AbuBakar ${ }^{1 凶}$ \\ 1. Tropical Infectious Diseases Research and Education Center (TIDREC), Department of Medical Microbiology, Faculty of Medicine, \\ University of Malaya, Kuala Lumpur, Malaysia. \\ 2. Department of Social and Preventive Medicine, Faculty of Medicine, University of Malaya, Kuala Lumpur, Malaysia.
}

\begin{abstract}
$\bowtie$ Corresponding author: Email: sazaly@um.edu.my Telefax: +60379675757.
(c) Ivyspring International Publisher. This is an open-access article distributed under the terms of the Creative Commons License (http://creativecommons.org/ licenses/by-nc-nd/3.0/). Reproduction is permitted for personal, noncommercial use, provided that the article is in whole, unmodified, and properly cited.
\end{abstract}

Received: 2014.03.03; Accepted: 2014.12.09; Published: 2015.01.12

\begin{abstract}
Dengue virus (DENV) infection usually presents with mild self-limiting dengue fever (DF). Few however, would present with the more severe form of the disease, dengue hemorrhagic fever (DHF) and dengue shock syndrome (DSS). In the present study, the association between IL-12B, IL-10 and TNF- $\alpha$ gene polymorphisms and dengue severity was investigated. Methods: A case-control study was performed on a total of 120 unrelated controls, 86 DF patients and 196 DHF/DSS patients. The polymorphisms in IL-12B, IL-10 and TNF- $\alpha$ genes were genotyped using PCR-RFLP and PCR-sequencing methods. Results: A protective association of TNF- $\alpha-308 \mathrm{~A}$ allele and -308GA genotype against DHF/DSS was observed, while TNF- $\alpha-238 \mathrm{~A}$ allele and -238GA genotype were associated with DHF/DSS. A combination of TNF- $\alpha-308 \mathrm{GA}+\mathrm{AA}$ genotype and IL-10 non-GCC haplotypes, IL-12B pro homozygotes (prol/prol, pro2/pro2) and IL-12B 3'UTR $A C$ were significantly correlated with protective effects against DHF/DSS. An association between the cytokine gene polymorphisms and protection against the clinical features of severe dengue including thrombocytopenia and increased liver enzymes was observed in this study. Conclusion: The overall findings of the study support the correlation of high-producer TNF- $\alpha$ genotypes combined with low-producer IL-10 haplotypes and IL-12B genotypes in reduced risk of DHF/DSS.
\end{abstract}

Key words: Infectious disease, tropical, dengue, genetics, cytokine, polymorphism.

\section{Introduction}

Dengue is one of the most important arthropod-borne diseases in the tropics and subtropics region of the world. It is a disease of public health concern in over 125 countries [1]. At least four dengue virus (DENV) serotypes; DENV-1, DENV-2, DENV-3, and DENV-4 are known to cause dengue. The virus is usually transmitted to human through bites of infected Aedes mosquitoes. Most who contracted dengue present with a mild self-limiting fever, dengue fever (DF). Only $1-2 \%$ of the infected person would present with the more severe form of the disease known as dengue hemorrhagic fever (DHF) and dengue shock syndrome (DSS). DHF is usually characterized by vascular leakage, marked thrombocytopenia and hemorrhagic manifestations while DSS is the progression of DHF accompanied with hypovolemic shock and hypotension [2, 3]. If not adequately treated, DHF and DSS could lead to death. At least 22,000 dengue deaths are reported annually [4].

To date, the pathogenesis of DHF/DSS remained not well understood. A number of hypotheses have been forwarded and these include the pathogenic effects of highly virulent variants of DENV [5] and the involvement of exaggerated host immune response 
[6-8]. Higher risk of contracting DHF/DSS in individuals with previous exposure to DENV has been well-documented [9, 10]. Evidences supporting the importance of antibody-dependent enhancement (ADE) of infection and T cell 'original antigenic sin' in induction of severe dengue have been presented. Alteration in the cytokine and $\mathrm{T}$ helper (Th) cell responses in secondary DENV infection has been described in the pathogenesis of severe dengue $[6,7]$.

Most evidences suggesting either protective or pathological role of cytokines in severe dengue, however, have been derived mainly from the clinical and epidemiological studies. A number of studies for instance have reported higher serum levels of antiand pro-inflammatory cytokines such as interleukin-1 beta (IL-1 $\beta$ ), IL-2, IL-6, IL-8, IL-10, IL-13, IL-18 and tumor necrosis factor alpha (TNF- $\alpha$ ) in DHF/DSS patients [11-14]. Other studies, however, revealed variations in the results as some did not find differences in the cytokine production. Several in vitro studies demonstrated that ADE in DENV infection induces IL-10 mediated immunosuppression with diminished production of antiviral nitric oxide (NO) and pro-inflammatory cytokines including IL-12, interferon gamma (IFN- $\gamma$ ) and TNF- $\alpha[15,16]$, while other reports showed increased production of IL-10, IFN- $\alpha$, and TNF- $\alpha$ [17].

The role of human genetics in determining susceptibility to infectious diseases has been reviewed [18]. Earlier studies in other diseases have shown that polymorphisms at the IL-10, IL-12B and TNF- $\alpha$ influence production of these cytokines [19-25] contributing to the varied individual immune response to stimuli. It is similarly postulated that these polymorphisms could also influence the cytokine response profile during early stage of DENV infection, leading to differences in the immune response pattern and thus the outcome of the disease. Here we investigated the possible influence of the IL-12B, IL-10 and TNF- $\alpha$ promoter polymorphisms in protection and/or predisposition to severe dengue.

\section{Materials and Methods}

\section{Dengue patients and controls}

The present study was approved by the University Malaya Medical Center (UMMC) Medical Ethics Committee (ethics committee/ IRB reference number: 611.10). A total of 282 clinically dengue-diagnosed patients from UMMC during the year 2006-2007 were retrospectively enrolled into the study (informed consents were not obtained from these patients). Clinical records and laboratory findings of the dengue patients were obtained and reviewed. Clinical classification of dengue as DF, DHF and DSS was per- formed according to the World Health Organization (WHO) 1997 guideline [2]. This was done as the clinical notes were all in accordance to the WHO 1997 guideline. Patients' clotted blood samples were obtained from the Microbiology Laboratory Diagnostic Repository for genomic DNA extraction. The control group of this study consisted of 120 unrelated, gender and ethnicity-matched healthy volunteers tested negative for anti-dengue IgG antibodies. Their blood samples were obtained with written consents for genomic DNA extraction.

\section{Detection of gene polymorphisms in IL-10 promoter gene, IL-12B and TNF- $\alpha$ promoter gene}

Human genomic DNA was extracted from approximately $400 \mu$ of pulverized clotted blood using QIAamp DNA Mini Kit (Qiagen, Hilden, Germany). Genomic DNA was eluted in $200 \mu \mathrm{l}$ of nuclease-free water and kept at $-20^{\circ} \mathrm{C}$ until needed.

The IL-12B 3'UTR Taq I polymorphism (rs3212227) and the two single nucleotide polymorphisms (SNPs) of the IL-10 gene promoter at the position -592 (rs1800872) and -1082 (rs1800896) were genotyped using polymerase chain reaction (PCR) coupled with restriction fragment length polymorphisms (RFLP) [26, 27]. PCR amplification of IL-10 -592, -1082 and IL-12B 3'UTR fragments were performed by adding $1 \mu \mathrm{l}$ of extracted DNA into a volume of $24 \mu \mathrm{l}$ reaction containing nuclease-free water, $1 \times$ GoTaq ${ }^{\circledR}$ Flexi Buffer (Promega, USA), $1.5 \mathrm{mM} \mathrm{MgCl} 2,0.2 \mathrm{mM}$ dNTPs, 2.5 units of GoTaq ${ }^{\circledR}$ DNA Polymerase (Promega, USA), and $0.6 \mathrm{pmol}$ of each forward and reverse primer (Table 1). The PCR reactions for each fragment were performed at conditions summarized in Table 2. Amplified IL-10 -592 and -1082 fragments were subsequently treated with $12 \mathrm{U}$ of Rsal (Promega, USA) and $10 \mathrm{U}$ of Mnl I (New England Biolabs, UK) at $37^{\circ} \mathrm{C}$ for $1 \mathrm{hr}$ and $1.5 \mathrm{hr}$, respectively. Amplified IL-12B 3'UTR fragment was digested with $10 \mathrm{U}$ of Taq I at $65^{\circ} \mathrm{C}$ for $2 \mathrm{hr}$. The restriction patterns were examined by gel electrophoresis (Table 2).

The IL-10 -819 SNP (rs1800871) was not genotyped as there is complete linkage disequilibrium between IL-10 -819 and -592 SNPs. Furthermore, PCR-RFLP genotyping results of IL-10 promoter SNPs in at least half of the samples was verified by nucleotide sequencing of the IL-10 promoter fragment amplified using primer FP-592 and RP-1082 (Table 1). Sequencing was performed in one direction using the BigDye Terminator v3.1 Cycle Sequencing Kit on a capillary DNA sequencer 3730xl DNA analyser (Applied Biosystems, USA). 
Table 1. Primers for the detection of IL-10, ILI2B and TNF- $\alpha$ gene polymorphisms.

\begin{tabular}{lll}
\hline Gene Polymorphisms & Genotyping Method & Primer Sequence $\left(5^{\prime} \rightarrow 3^{\prime}\right)$ \\
\hline IL10-C592A (rs 1800872) & PCR-RFLP & FP-592: CCTAGGTCACAGTGACGTGG \\
& & RP-592: GGTGAGCACTACCTGACTAGC \\
IL10-A1082G (rs 1800896) & PCR-RFLP & RP-1082: AGGTCCCTTACTTGCTCTTACC \\
& & FP1: ATTTGGAGGAAAACCCAACTG \\
IL12B 3'UTR Taq I A/C (rs 3212227) & PCR-RFLP & FP: AATTTCATGTCCTTAGCCATA \\
& & RP1: ATTGGTCCTTCTGTTTGTCCTAA TGTGGGGGCCACATTAGAG \\
IL12B pro (rs 17860508) & PCR allele-specific & RP2: TCTAATGTGGGGGCACAGC \\
& & G308F: AGAAATGGAGGCAATAGGTTT TGAIIIIIATGGGG \\
TNF- $\alpha-G 308$ A (rs 1800629) & G308R: CTCTGCTGTCCTTGCTGAGIIIII GTCTGC \\
& & A308F: GGCCTCAGGACTCAACACIIIIT TCCCTC \\
& & A308R: GGACCCTGGAGGCTGAAIIIITC CTCA \\
\hline
\end{tabular}

Table 2. PCR conditions and gel electrophoresis setting for the genotyping of IL-10, IL12B and TNF- $\alpha$ gene polymorphisms.

\begin{tabular}{|c|c|c|}
\hline Gene Polymorphisms & PCR Thermal Condition & Gel electrophoresis \\
\hline IL10-C592A & $95^{\circ} \mathrm{C}$ for $2 \mathrm{~min}, 35 \mathrm{cycles}$ of $94^{\circ} \mathrm{C}$ for $30 \mathrm{sec}, 60^{\circ} \mathrm{C}$ for $45 \mathrm{sec}, 72^{\circ} \mathrm{C}$ for $1 \mathrm{~min}$, final $72^{\circ} \mathrm{C}$ for $10 \mathrm{~min}$ & $2.5 \%$ agarose gel \\
\hline IL10-A1082G & $95^{\circ} \mathrm{C}$ for $3 \mathrm{~min}, 40 \mathrm{cycles}$ of $94^{\circ} \mathrm{C}$ for $30 \mathrm{sec}, 66^{\circ} \mathrm{C}$ for $30 \mathrm{sec}, 72^{\circ} \mathrm{C}$ for $30 \mathrm{sec}$, final $72^{\circ} \mathrm{C}$ for $2 \mathrm{~min}$ & $4 \%$ MetaPhor ${ }^{\mathrm{TM}}$ agarose gel \\
\hline IL12B-3UTR Taq I A/C & $95^{\circ} \mathrm{C}$ for $10 \mathrm{~min}, 35 \mathrm{cycles}$ of $94^{\circ} \mathrm{C}$ for $1 \mathrm{~min}, 54^{\circ} \mathrm{C}$ for $1 \mathrm{~min}, 72^{\circ} \mathrm{C}$ for $2 \mathrm{~min}$, final $72^{\circ} \mathrm{C}$ for $7 \mathrm{~min}$ & $2.5 \%$ agarose gel \\
\hline IL12B pro & $95^{\circ} \mathrm{C}$ for $10 \mathrm{~min}, 35 \mathrm{cycles}$ of $94^{\circ} \mathrm{C}$ for $1 \mathrm{~min}, 54^{\circ} \mathrm{C}$ for $1 \mathrm{~min}, 72^{\circ} \mathrm{C}$ for $2 \mathrm{~min}$, final $72^{\circ} \mathrm{C}$ for $7 \mathrm{~min}$ & $3.5 \%$ agarose gel \\
\hline TNF- $\alpha-G 308 A$ & $95^{\circ} \mathrm{C}$ for $2 \mathrm{~min}, 35 \mathrm{cycles}$ of $94^{\circ} \mathrm{C}$ for $30 \mathrm{sec}, 66^{\circ} \mathrm{C}$ for $1 \mathrm{~min}, 72^{\circ} \mathrm{C}$ for $1 \mathrm{~min}$, final $72^{\circ} \mathrm{C}$ for $2 \mathrm{~min}$ & $2.0 \%$ agarose gel \\
\hline
\end{tabular}

Allele-specific primers [21] were used to detect IL-12Bpro (CTCTAA/GC) polymorphisms (rs17860508) (Table 1). PCR amplification of IL-12B promoter region was performed in a total volume of $25 \mu \mathrm{l}$ PCR reaction containing nuclease-free water, 1× GoTaq ${ }^{\circledR}$ Flexi Buffer (Promega, USA), $1.5 \mathrm{mM} \mathrm{MgCl}{ }_{2}$, $0.2 \mathrm{mM}$ dNTPs, 2.5 units of GoTaq ${ }^{\circledR}$ DNA Polymerase (Promega, USA), 0.6 pmol of each forward and reverse primer (Table 1) and the extracted DNA. The PCR conditions are summarized in Table 2.

The TNF- $\alpha-308$ SNP (rs1800629) was genotyped by using dual priming oligonucleotide (DPO) primer-based duplex PCR. The SNP specific DPO primers were designed based on the principle described earlier [28]; in each primer a single variation was located at the middle of $3^{\prime}$ segment for accurate discrimination. PCR amplification was performed in a total of $15 \mu \mathrm{l}$ reaction containing nuclease-free water, $1 \times$ MyTaq Mix, 0.6 pmol of each primer G308R and A308F, 0.3 pmol of each primer G308F and A308R, and the extracted DNA. Genotyping of TNF- $\alpha-308$ SNP were further validated in all samples by sequencing the $527 \mathrm{bp}$ TNF- $\alpha$ promoter fragment amplified using primers TNFa-F $5^{\prime}$ GGCCTCAGGACTCAACACAGC $3^{\prime}$ and TNFa-R 5' CTTGCTGAGGGAGCGTCTGC $3{ }^{\prime}$. Sequencing was performed bi-directionally with both forward and reverse primers using the BigDye Terminator v3.1 Cycle Sequencing Kit on a capillary DNA sequencer 3730xl DNA analyser (Applied Biosystems, USA). The TNF- $\alpha$ promoter SNPs at positions -238 (rs361525) and -376 (rs1800750) were identified from the sequencing data.

\section{Statistical Analysis}

A Pearson Chi-square was used to determine whether the observed frequencies of gene polymorphism genotypes conformed to Hardy-Weinberg equilibrium expectations. The genotype and allele frequencies were compared between patient groups by using a chi-square or Fisher's exact test. A two-sided $p$ value $<0.05$ was considered to be statistically significant. The correlation between the polymorphism genotypes and dengue severity was assessed by the odds ratio (OR) with corresponding 95\% confidence intervals (CIs). All statistical analysis was performed using IBM SPSS Statistics, version 21 (IBM Corporation, New York, United States) and GraphPad Prims 5.01 (GraphPad Software Inc, La Jolla, CA, USA).

\section{Results}

\section{Demographics, clinical presentations and laboratory findings of DF and DHF/DSS patients}

In this study, 282 clinically diagnosed dengue patients were recruited. Using the WHO 1997 guideline, 86 patients were classified as DF, 182 were DHF and 14 were DSS. The median age of DF and DHF/DSS groups was 26 years (range 0.3-66 years) and 28 years (range $0.8-81$ years), respectively. The proportion of male and female among DF patients was similar, while male showed preponderance among the DHF/DSS group (OR=2.0 [95\% $\mathrm{CI}=1.2-3.3], \mathrm{p}=0.01$ ) (Table 3). The ethnic composition of dengue patients was paralleled to that of the total 
dengue patients presented to UMMC, majority of which were Malay (52.5\%), followed by Chinese $(17.4 \%)$, Indian $(17.0 \%)$ and other races $(12.4 \%)$.

The clinical features and laboratory findings of the dengue patients are summarized in Table 3 . The presence of plasma leakage including ascites, pleural effusion and hemoconcentration distinguished DHF/DSS from DF $(p<0.001$, Table 3). Tachycardia and restlessness were only detected among the DHF/DSS patients. Presentation of abdominal pain, and hepatomegaly were also statistically associated with DHF/DSS patients in comparison to DF patients $(p<0.05)$. Vomiting, even though not statistically significant $(\mathrm{OR}=1.7$ [95\% $\mathrm{CI}=0.98-2.9], \mathrm{p}<0.07)$, was more frequent in DHF/DSS than in DF. On the other hand, thrombocytopenia (platelet count $<100 \times 10^{9} / \mathrm{L}$ ) and increased aspartate aminotransferase (AST) and alanine aminotransferase (ALT) $(>1000 \mathrm{IU} / \mathrm{L})$ were statistically significant in DHF/DSS patients. Leucopenia was common in both DF and DHF/DSS groups.

Dengue virus infection was confirmed in 275 patients by either serology (anti-dengue IgM and/or anti-dengue IgG [Standard Diagnosis Inc., Korea]), dengue NS1 antigen detection (Bio-Rad Laboratories, France), or virus isolation. Dengue IgM was negative in 7 patients ( 5 DF patients, 2 DHF patients); there was no record of other complimentary tests in these patients. On the other hand, there was no record of laboratory dengue testing in 1 DHF patient.

\section{Distribution of TNF- $\alpha$, IL-1 2B and IL-1 0 gene promoter polymorphisms among DF, DHF/DSS and control groups}

Overall, genotyping of TNF- $\alpha$, IL-12B and IL-10 gene promoter SNPs was successful in at least $98 \%$ $(n=396)$ of the studied patients. The distributions of all gene alleles and genotypes were consistent to the Hardy-Weinberg equilibrium, except for the IL-12B 3'UTR Taq I polymorphism in the control group. The frequencies of alleles and genotypes for the corresponding cytokine genes among the dengue patients and control group were summarized in Table 4 . The TNF- $\alpha \quad-308 \mathrm{~A}$ allele (OR=0.4 [95\% CI=0.2-0.8], $\mathrm{p}=0.007)$ and $-308 \mathrm{GA}$ genotype $(\mathrm{OR}=0.4 \quad[95 \%$ $\mathrm{CI}=0.2-0.8], \mathrm{p}=0.014)$ were distributed at decreased frequencies in the DHF/DSS patients in comparison to the control group. Among the DHF/DSS patients, the frequency of -308GG genotype was significantly higher compared to that of the control group $(\mathrm{OR}=2.5$ [95\% CI=1.3-4.9], $\mathrm{p}=0.007)$. In contrast, increased frequencies of $-238 \mathrm{~A}$ allele (OR=4.8 [95\% CI=1.1-21.0], $\mathrm{p}=0.023)$ and $-238 \mathrm{GA}$ genotype $(\mathrm{OR}=4.9 \quad[95 \%$ $\mathrm{CI}=1.1-21.9], \mathrm{p}=0.021)$ were found among DHF/DSS group in comparison to the control group. The rare $-376 \mathrm{~A}$ allele was detected at very low frequency $(<0.4 \%)$ among our study population and thus was excluded from further analysis. In our study, the -376 allele distribution did not differ between all groups.

Table 3. Demographic, clinical and laboratory findings of dengue patients.

\begin{tabular}{|c|c|c|c|c|}
\hline & $\mathrm{DF}(\mathrm{n}=86)$ & DHF $(n=196)$ & p-value (Fishers') & OR; $95 \% \mathrm{CI}$ \\
\hline Median age (range) & $26(0.3-66)$ & $28(0.8-81)$ & 0.506 & \\
\hline Gender (Male:Female) & $39: 47$ & $122: 74$ & 0.009 & $1.99 ; 1.19-3.32$ \\
\hline Race (Malay:Chinese:Indian:Others) & $\begin{array}{l}\text { 47:17:11:11 } \\
55: 20: 13: 13 \%\end{array}$ & $\begin{array}{l}\text { 101:32:37:24 } \\
\text { 52:17:19:12\% }\end{array}$ & & \\
\hline Symptoms and signs & $\mathrm{n}(\%)$ & $\mathrm{n}(\%)$ & & \\
\hline Headache & $51(59.3)$ & $121(61.7)$ & 0.694 & \\
\hline Retro-orbital pain & $13(15.1)$ & $27(13.8)$ & 0.853 & \\
\hline Abdomial pain & $28(32.6)$ & $98(50.0)$ & 0.009 & $2.03 ; 1.19-3.45$ \\
\hline Rash & $50(58.1)$ & $106(54.1)$ & 0.606 & \\
\hline Myalgia & $75(87.2)$ & $156(79.6)$ & 0.188 & \\
\hline Arthralgia & $39(45.3)$ & $78(39.8)$ & 0.434 & \\
\hline Vomiting & $52(60.5)$ & $141(71.9)$ & 0.070 & $1.68 ; 0.98-2.86$ \\
\hline Diarrhea & $38(44.2)$ & $107(54.6)$ & 0.122 & \\
\hline Bleeding manifestations & $49(57.0)$ & $119(60.7)$ & 0.601 & \\
\hline Ascites & $0(0.0)$ & $152(77.6)$ & $<0.001$ & $573.1 ; 34.84-9427$ \\
\hline Pleural effusion & $0(0.0)$ & $129(65.8)$ & $<0.001$ & $339.3 ; 20.70-5561$ \\
\hline Hepatomegaly & $19(22.1)$ & $99(50.5)$ & $<0.001$ & $3.60 ; 2.01-6.43$ \\
\hline Lethargy & $19(22.1)$ & $62(31.6)$ & 0.117 & \\
\hline Giddiness & $25(29.1)$ & $57(29.1)$ & 1.000 & \\
\hline Shortness of breath & $4(4.7)$ & $18(9.2)$ & 0.233 & \\
\hline Tachycardiac & $0(0.0)$ & $9(4.6)$ & 0.061 & \\
\hline Restless & $0(0.0)$ & $10(5.1)$ & 0.035 & $9.85 ; 0.57-170.10$ \\
\hline \multicolumn{5}{|l|}{ Laboratory Findings } \\
\hline Hemoconcentration (hematocrit $\geq 20 \%$ ) & $0(0.0)$ & $85(43.4)$ & $<0.001$ & $131.5 ; 8.04-2151$ \\
\hline Thrombocytopenia $\left(<100 \times 10^{9} / \mathrm{L}\right)$ & $78(90.7)$ & $193(98.5)$ & 0.009 & $4.95 ; 1.45-16.91$ \\
\hline Decreased white cell count $\left(<4000 / \mathrm{mm}^{3}\right)$ & $71(82.6)$ & $144(73.5)$ & 0.128 & \\
\hline Increased AST (> 1000IU/L) & $58(67.4)$ & $170(86.7)$ & 0.003 & $2.71 ; 1.44-5.08$ \\
\hline Increased ALT (> 1000IU/L) & $47(54.7)$ & $149(76.0)$ & 0.002 & $2.41 ; 1.39-4.18$ \\
\hline
\end{tabular}

Dengue fever (DF); Dengue hemorrhagic fever (DHF); Alanine aminotransferase (ALT); Aspartate aminotransferase (AST); Odds ratio (OR); Confidence intervals (CI) 
Table 4. Frequency of IL-10, ILI2B and TNF- $\alpha$ gene polymorphism genotypes among the dengue patients and healthy control group.

\begin{tabular}{|c|c|c|c|c|}
\hline \multicolumn{2}{|l|}{ Gene } & DF n (\%) & DHF n (\%) & Control n (\%) \\
\hline \multicolumn{5}{|l|}{$\overline{\text { IL12B }}$} \\
\hline \multirow[t]{2}{*}{ Allele } & IL12B pro1 & $82(47.7)$ & $177(45.4)$ & $104(43.3)$ \\
\hline & IL12B pro2 & $90(52.3)$ & $213(54.6)$ & $136(56.7)$ \\
\hline \multirow[t]{3}{*}{ Genotype } & IL12B pro1/pro1 & $16(18.6)$ & $40(20.5)$ & $20(16.7)$ \\
\hline & IL12B pro1/pro2 & $50(58.1)$ & 97 (49.7) & $64(53.3)$ \\
\hline & IL12B pro2/pro2 & $20(23.3)$ & $58(29.7)$ & $36(30.0)$ \\
\hline \multicolumn{5}{|c|}{ IL12B-3UTR } \\
\hline \multirow[t]{2}{*}{ Allele } & A & $98(57.0)$ & 232 (59.8) & 143 (61.6) \\
\hline & $\mathrm{C}$ & $74(43.0)$ & $156(40.2)$ & $89(38.4)$ \\
\hline \multirow[t]{3}{*}{ Genotype } & AA & $26(30.2)$ & $66(34.0)$ & $38(32.8)$ \\
\hline & $\mathrm{AC}$ & $46(50.5)$ & $100(51.5)$ & $67(57.8)$ \\
\hline & $\mathrm{CC}$ & $14(16.3)$ & $28(14.4)$ & $11(9.5)$ \\
\hline \multicolumn{5}{|l|}{ IL10-1082 } \\
\hline \multirow[t]{2}{*}{ Allele } & G & 21 (12.2) & $42(10.8)$ & $16(6.8)$ \\
\hline & A & $151(87.8)$ & $348(89.2)$ & $220(93.2)$ \\
\hline \multirow[t]{3}{*}{ Genotype } & GG & $1(1.2)$ & $1(0.5)$ & $0(0.0)$ \\
\hline & AG & $17(19.8)$ & $40(20.5)$ & $16(13.6)$ \\
\hline & AA & 68 (79.1) & $154(79.0)$ & $102(86.4)$ \\
\hline \multicolumn{5}{|l|}{ IL10-819 } \\
\hline \multirow[t]{2}{*}{ Allele } & C & $61(35.5)$ & $132(34.2)$ & $74(31.1)$ \\
\hline & $\mathrm{T}$ & $111(64.5)$ & $254(65.8)$ & $164(68.9)$ \\
\hline \multirow[t]{3}{*}{ Genotype } & $\mathrm{CC}$ & $13(15.1)$ & $26(13.5)$ & $13(10.9)$ \\
\hline & $\mathrm{CT}$ & 35 (40.7) & 80 (41.5) & $48(40.3)$ \\
\hline & TT & $38(44.2)$ & 87 (45.1) & $58(48.7)$ \\
\hline \multicolumn{5}{|l|}{ IL10-592 } \\
\hline \multirow[t]{2}{*}{ Allele } & C & $61(35.5)$ & $132(34.2)$ & $74(31.1)$ \\
\hline & A & $111(64.5)$ & $254(65.8)$ & $164(68.9)$ \\
\hline \multirow[t]{3}{*}{ Genotype } & $\mathrm{CC}$ & $13(15.1)$ & $26(13.5)$ & $13(10.9)$ \\
\hline & $\mathrm{CA}$ & $36(41.9)$ & $81(42.0)$ & $48(40.3)$ \\
\hline & $\mathrm{AA}$ & $37(43.0)$ & $86(44.6)$ & $58(48.7)$ \\
\hline \multicolumn{5}{|l|}{ TNFa-376 } \\
\hline \multirow[t]{2}{*}{ Allele } & G & 169 (99.4) & 388 (99.5) & $240(100.0)$ \\
\hline & A & $1(0.6)$ & $2(0.5)$ & $0(0.0)$ \\
\hline \multirow[t]{3}{*}{ Genotype } & GG & 84 (98.8) & $193(99.0)$ & $120(100.0)$ \\
\hline & GA & $1(1.2)$ & $2(1.0)$ & $0(0.0)$ \\
\hline & AA & $0(0.0)$ & $0(0.0)$ & $0(0.0)$ \\
\hline \multicolumn{5}{|l|}{ TNFa-308 } \\
\hline \multirow[t]{2}{*}{ Allele } & G & $159(92.4)$ & $373(95.6)^{\mathrm{a}}$ & $216(90.0)$ \\
\hline & $\mathrm{A}$ & $13(7.6)$ & $17(4.4)^{\mathrm{b}}$ & $24(10.0)$ \\
\hline \multirow[t]{3}{*}{ Genotype } & GG & $74(86.0)$ & $178(91.3)^{c}$ & $97(80.8)$ \\
\hline & GA & $11(12.8)$ & $17(8.7)^{\mathrm{d}}$ & 22 (18.3) \\
\hline & AA & $1(1.2)$ & $0(0.0)$ & $1(0.8)$ \\
\hline TNFa-238 & & & & \\
\hline Allele & G & $164(96.5)$ & $375(96.2)^{\mathrm{e}}$ & $238(99.2)$ \\
\hline & A & $6(3.5)$ & $15(3.8)^{\mathrm{f}}$ & $2(0.8)$ \\
\hline Genotype & GG & $80(94.1)$ & $180(92.3) \mathrm{g}$ & $118(98.3)$ \\
\hline & GA & $4(4.7)$ & $15(7.7)^{\mathrm{h}}$ & $2(1.7)$ \\
\hline & AA & $1(1.2)$ & $0(0.0)$ & $0(0.0)$ \\
\hline
\end{tabular}

aIncreased in DHF in comparison to control $(\mathrm{p}=0.007, \mathrm{OR}=2.44,95 \% \mathrm{CI}=1.28-4.64)$ becreased in DHF in comparison to control $(\mathrm{p}=0.007, \mathrm{OR}=0.41,95 \% \mathrm{CI}=0.22-0.78)$ Increased in DHF in comparison to control $(\mathrm{p}=0.009, \mathrm{OR}=2.48,95 \% \mathrm{CI}=1.27-4.87)$ dDecreased in DHF in comparison to control $(\mathrm{p}=0.014, \mathrm{OR}=0.43,95 \% \mathrm{CI}=0.22-0.84)$ eDecreased in DHF in comparison to control $(p=0.023$, OR=0.21, 95\% CI $=0.05-0.93)$ Increased in DHF in comparison to control $(\mathrm{p}=0.023, \mathrm{OR}=4.76,95 \% \mathrm{CI}=1.08-21.01)$ gDecreased in DHF in comparison to control $(p=0.021, O R=0.20,95 \% C I=0.05-0.90)$ hIncreased in DHF in comparison to control $(\mathrm{p}=0.021, \mathrm{OR}=4.92,95 \% \mathrm{CI}=1.10-21.90)$

The distributions of IL-12Bpro and IL-12B 3'UTR gene variants were similar between all groups (Table $4)$. The pro1 (CTCTAA) and pro2 (GC) alleles of IL-12Bpro were equally distributed among our study population; the pro1/pro2 heterozygote was the predominant genotype. Similarly, the AC heterozygous genotype of IL-12B 3'UTR was predominant in our study population, followed by AA and CC genotypes (Table 4). Further, all three IL-10 promoter SNPs at position $-1082,-819$ and -592 distributed similarly among all groups. The IL-10 promoter haplotypes were formed by the 3 bi-allelic SNPs (Table 5). Our findings revealed three haplotypes in the population; ATA, ACC and GCC. Non-GCC haplotypes (ATA/ATA, ATA/ACC, or ACC/ACC) was predominant $(81.2 \%)$ in the Malaysia population, while the GCC haplotypes (ATA/GCC, ACC/GCC, or GCC/GCC) was relatively less frequent. The GCC haplotypes, even though was not statistically significant, was more frequently distributed in DHF/DSS patients $(20.5 \%)$ than in control group (13.6\%) (Table 5).

The distributions of the combined cytokine gene genotypes were summarized in Table 5. In comparison to the control group, three combined genotypes were detected at significantly lower frequencies among the DHF/DSS patients: the TNF- $\alpha$ -308GA+AA/IL-10 non-GCC haplotypes (OR $=0.3$ [95\% CI=0.2-0.7], $\quad \mathrm{p}=0.002)$, the TNF- $\alpha$ -308GA+AA/IL-12Bpro homozygote (pro1/pro1+ pro2/pro2) (OR=0.4 [95\% CI=0.2-1.0], $\mathrm{p}=0.042)$, and the TNF- $\alpha-308 \mathrm{GA}+\mathrm{AA} / \mathrm{IL}-12 \mathrm{~B}$ 3'UTR AC (OR=0.3 [95\% CI=0.1-0.8], $\mathrm{p}=0.026$ ) (Table 5). The distribution of these combined genotypes, however, was not different between DF and DHF/DSS or the control group.

A segregation analysis based on the gender of the study population was performed. No differences in genetic association in dengue severity were observed between the male and female. Association was found only with the combined genotype of IL-10 non-GCC/TNF- $\alpha$-308GA/AA, where the genotype frequency was significantly decreased in the DHF/DSS patients in comparison to the control group, among male $(\mathrm{OR}=0.3 \quad$ [95\% $\mathrm{CI}=0.1-0.9]$, $\mathrm{p}=0.035)$ and female (OR=0.4 [95\% CI=0.2-0.9], $\mathrm{p}=0.046)$. There was no significant difference detected in the distributions of other alleles, genotypes or combined genotypes between all groups.

\section{Association between TNF- $\alpha$, IL-12B and IL-10 gene promoter polymorphisms and clinical features of dengue}

No significant differences in the frequencies of gene polymorphisms between DF and DHF/DSS patients were observed in our study. Here, the dengue patient population was stratified based on the clinical presentations and analyzed for the distribution of gene polymorphisms. Our findings revealed gene associations between the TNF- $\alpha-308$, IL-10 and 
IL-12B genotypes and the distinctive clinical presentations of DHF/DSS as shown in Table 6. The association with thrombocytopenia was the most significant, in which the frequencies of TNF- $\alpha-308 \mathrm{GA}+\mathrm{AA}$ genotypes, IL-12B 3'UTR AC and the combination of genotypes IL-10 non-GCC haplotypes, IL-12B heterozygote (pro1/pro2) and TNF- $\alpha-308 \mathrm{GA}+\mathrm{AA}$ were significantly reduced in those presenting thrombocytopenia $(p<0.05$, Table 6$)$. Similar associations were also found between the similar genotypes with presentations including increased AST and ALT, hemoconcentration, hepatomegaly and abdominal pain prominent in severe dengue (Table 6).

Table 5. Combination of IL-10, IL12B and TNF- $\alpha$ gene polymorphisms among the dengue patients and control population.

\begin{tabular}{|c|c|c|c|}
\hline Gene & DF n $(\%)$ & DHF n $(\%)$ & Control n (\%) \\
\hline \multicolumn{4}{|l|}{ IL10 haplotypes } \\
\hline Non-GCC (ATA/ATA, ACC/ACC, ATA/ACC) & $68(79.1)$ & $154(79.0)$ & $102(86.4)$ \\
\hline Heterozygous (ATA/GCC, ACC/GCC) & $17(19.8)$ & $40(20.5)$ & $16(13.6)$ \\
\hline Homozygous GCC & $1(1.2)$ & $1(0.5)$ & $0(0.0)$ \\
\hline \multicolumn{4}{|l|}{ TNFa-308/IL10 haplotypes } \\
\hline -308GG/IL-10 Non-GCC (ATA/ACC, ACC/ACC, ATA/ACC) & $58(68.2)$ & $139(71.6)$ & $79(66.9)$ \\
\hline -308GG/IL-10 GCC (ATA/GCC, ACC/GCC, GCC/GCC) & $15(17.6)$ & $38(19.6)$ & $16(13.6)$ \\
\hline$-308 \mathrm{GA}+\mathrm{AA} / \mathrm{IL}-10 \mathrm{Non}-\mathrm{GCC}$ & $9(10.6)$ & $14(7.2)^{\mathrm{a}}$ & $23(19.5)$ \\
\hline$-308 \mathrm{GA}+\mathrm{AA} / \mathrm{IL}-10 \mathrm{GCC}$ & $3(3.5)$ & $3(1.5)$ & $0(0.0)$ \\
\hline \multicolumn{4}{|l|}{ IL12B/IL10 haplotypes } \\
\hline (pro1/pro2)/ IL-10 Non-GCC & $40(47.1)$ & $71(36.6)$ & $54(45.8)$ \\
\hline (pro1/pro2)/ IL-10 GCC & $9(10.6)$ & $26(13.4)$ & $9(7.6)$ \\
\hline (pro1/pro1+pro2/pro2)/IL-10 Non-GCC & $27(31.8)$ & $82(42.3)$ & $48(40.7)$ \\
\hline (pro1/pro1+ pro2/pro2)/IL-10 GCC & $9(10.6)$ & $15(7.7)$ & $7(5.9)$ \\
\hline \multicolumn{4}{|l|}{ IL12B-3UTR/IL10 haplotypes } \\
\hline 3UTR AA/IL-10 Non-GCC & $18(20.9)$ & $50(25.8)$ & $30(26.3)$ \\
\hline 3UTR AA/IL-10 GCC & $8(9.3)$ & $16(8.2)$ & $6(5.3)$ \\
\hline 3UTR (AC+CC)/IL-10 Non-GCC & $50(58.1)$ & $103(53.1)$ & $69(60.5)$ \\
\hline 3UTR (AC+CC)/IL-10 GCC & $10(11.6)$ & $25(12.9)$ & $9(7.9)$ \\
\hline \multicolumn{4}{|l|}{ IL12B/TNFa-308 } \\
\hline (pro1/pro2)/-308GG & $43(50.6)$ & $89(45.9)$ & $54(45.0)$ \\
\hline (pro1/pro2)/-308GA+AA & $6(7.1)$ & $8(4.1)$ & $10(8.3)$ \\
\hline (pro1/pro1+pro2/pro2)/-308GG & $30(35.3)$ & $88(45.4)$ & $43(35.8)$ \\
\hline (pro1/pro1+pro2/pro2)/-308GA+AA & $6(7.1)$ & $9(4.6)^{\mathrm{b}}$ & $13(10.8)$ \\
\hline (pro1/pro1)/-308GG & $14(16.5)$ & $36(18.6)$ & $15(12.5)$ \\
\hline (pro1/pro1)/-308GA+AA & $2(2.4)$ & $4(2.1)$ & $5(4.2)$ \\
\hline (pro2/pro2)/-308GG & $16(18.8)$ & $52(26.8)$ & $28(23.3)$ \\
\hline$($ pro2/pro2)/-308GA+AA & $4(4.7)$ & $5(2.6)$ & $8(6.7)$ \\
\hline \multicolumn{4}{|l|}{ IL12B-3UTR/TNFa-308 } \\
\hline 3UTR AA/-308GG & $24(27.9)$ & $60(30.9)$ & $32(27.6)$ \\
\hline 3UTR AA/-308GA+AA & $2(2.3)$ & $6(3.1)$ & $6(5.2)$ \\
\hline 3UTR AC/-308GG & $39(45.3)$ & $93(47.9)$ & $55(47.4)$ \\
\hline 3UTR AC/-308GA+AA & $7(8.1)$ & $7(3.6)^{c}$ & $12(10.3)$ \\
\hline 3UTR CC/-308GG & $11(12.8)$ & $24(12.4)$ & $7(6.0)$ \\
\hline 3UTR CC/-308GA+AA & $3(3.5)$ & $4(2.1)$ & $4(3.4)$ \\
\hline
\end{tabular}

aDecreased in DHF in comparison to control $(\mathrm{p}=0.002, \mathrm{OR}=0.32,95 \% \mathrm{CI}=0.16-0.65)$

bDecreased in DHF in comparison to control $(p=0.042, O R=0.40,95 \% \mathrm{CI}=0.17-0.97)$

cDecreased in DHF in comparison to control $(\mathrm{p}=0.026$, OR=0.32, 95\% CI $=0.12-0.85)$

Table 6. Associations between gene polymorphisms and clinical features of dengue.

\begin{tabular}{|c|c|c|c|c|}
\hline \multirow[b]{2}{*}{ Clinical Features } & \multirow[b]{2}{*}{ Gene Polymorphisms } & \multicolumn{3}{|c|}{ Fisher's Test } \\
\hline & & OR & $95 \% \mathrm{CI}$ & $\mathrm{p}$ value \\
\hline \multirow[t]{5}{*}{ Hemoconcetration } & IL12B-3UTR AA & 1.84 & $1.08-3.15$ & 0.026 \\
\hline & IL12B-3UTR AC & 0.54 & $0.32-0.92$ & 0.025 \\
\hline & IL12B-3UTR AC+CC & 0.54 & $0.32-0.93$ & 0.026 \\
\hline & IL12B-3UTR AA/TNF- $\alpha$-308GG & 1.94 & $1.13-3.35$ & 0.022 \\
\hline & IL12B-3UTR $(\mathrm{AC}+\mathrm{CC}) / \mathrm{TNF}-\alpha-308 \mathrm{GA}+\mathrm{AA}$ & 0.24 & $0.05-1.04$ & 0.045 \\
\hline \multirow[t]{6}{*}{ Thrombocytopenia } & TNF- $\alpha-308 G G$ & 7.29 & $2.15-24.75$ & 0.004 \\
\hline & TNF- $\alpha-308$ GA & 0.20 & $0.05-0.70$ & 0.023 \\
\hline & $\mathrm{TNF}-\alpha-308 \mathrm{GA}+\mathrm{AA}$ & 0.14 & $0.04-0.47$ & 0.004 \\
\hline & TNF- $\alpha-308$ GA+AA/IL-10 Non-GCC & 0.10 & $0.03-0.35$ & 0.001 \\
\hline & IL12B-3UTR AA & 13.10 & $0.77-223.9$ & 0.010 \\
\hline & IL12B-3UTR AC & 0.21 & $0.04-0.96$ & 0.037 \\
\hline
\end{tabular}




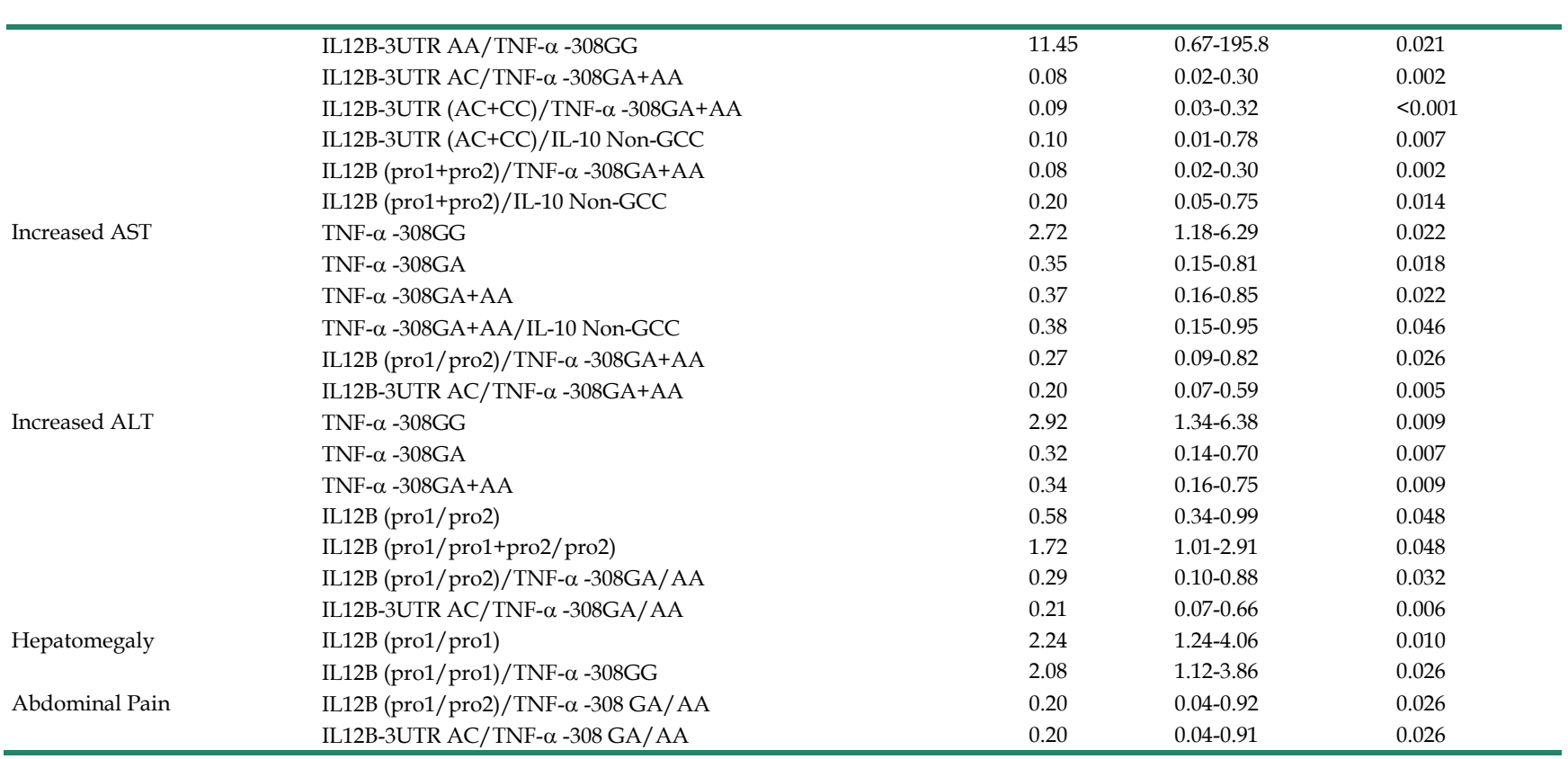

Alanine aminotransferase (ALT); Aspartate aminotransferase (AST); Odds ratio (OR); Confidence intervals (CI).

\section{Discussion}

In this study, we investigated the association of selected cytokine gene polymorphisms in severe dengue. Our findings revealed a protective association of TNF- $\alpha-308 \mathrm{~A}$ allele and -308GA genotype against DHF/DSS, while TNF- $\alpha-238 \mathrm{~A}$ allele and -238GA genotype were associated with manifestation of severe dengue. Combination of TNF- $\alpha-308 \mathrm{GA}+\mathrm{AA}$ genotype and IL-10 non-GCC haplotypes, IL-12B pro homozygotes (pro1/pro1, pro2/pro2) and IL-12B 3'UTR AC were significantly correlated with protective effects against DHF/DSS. Findings from our study also supported a correlation between the cytokine gene polymorphisms and the clinical features associated with severe and fatal dengue [3].

TNF- $\alpha$ polymorphisms were found important in dengue. While the $-308 \mathrm{~A}$ allele has been related to enhanced TNF- $\alpha$ gene transcriptional activity [20, 25], the $-238 \mathrm{~A}$ allele has been shown to reduce the TNF- $\alpha$ gene expression [19]. Our findings showed a correlation between the high-expressing TNF- $\alpha$ alleles and protection against DHF/DSS, suggesting a possible protective role of TNF- $\alpha$ in the pathogenesis leading to severe dengue. Our findings, even though contradict earlier reports which showed association between increased plasma level of TNF- $\alpha$ and DHF/DSS [29, 30], are consistent with in vitro reports showing important role of TNF- $\alpha$ in suppresing DENV infection $[15,31]$. The discrepancy in the observation between TNF- $\alpha$ in serum of DHF/DSS patients against that of in vitro results and in ours, is most likely because in the earlier, TNF- $\alpha$ is measured in patients who are already experiencing severe dengue where there are already massive pathological changes. In contrast, most DENV infections are either inapparent or subclinical $[32,33]$ suggesting effective control of virus infection early in the infection. While the antiviral immune response is early, most studies analyzed the cytokine production during dengue patients' defervescence stage of infection $[29,30]$.

TNF- $\alpha$ modulates acute inflammatory response to bacterial or viral infections and has been shown to be involved in viral clearance and host defense against infections with West Nile virus [34], encephalomyocarditis virus [35], Hepatitis B virus [36] and Influenza virus [37]. In dengue, it has been shown that transient suppression of TNF- $\alpha$ production during the early period of ADE infection in THP-1 cells promoted the initiation of DENV replication [15]. Yet in another study, TNF- $\alpha$ at high and medium concentration was shown to inhibit DENV replication in human dendritic cells, a primary DENV target cells [31]. Our finding of high TNF- $\alpha$ producing alleles being the protective traits against development of DHF/DSS, hence, is in agreement with these reports suggesting that high TNF- $\alpha$ secretion phenotype is likely to confer protective effects against severe dengue perhaps by suppressing the DENV load during the early infection phase.

Correlation between TNF- $\alpha-308 \mathrm{~A}$ allele and DHF has been reported earlier in patient population of Venezuela and Cuba $[38,39]$, but other studies did not find association in their group of patients [40-43]. A study in Mexico showed that the -238A allele was associated with protection of symptomatic dengue [41]. Similar to our findings, Vejbaesya et al identified the relation between the combined TNF- $\alpha$ 
-238A/lymphotoxin-alpha (LTA)-3 haplotype and DHF with secondary DENV infection [42]. The differences in results between the studies, however, may be due to the different populations examined. Perhaps there were enough similarities in the genetic background of Thais and Malaysians resulting in the consistent finding between the two populations in contrast to that performed in Venezuela and Mexico. In addition, limited sample size was noted in most of the earlier studies, in which the number of DHF patients used was less than $50[38,39,41]$. In contrast, the current study benefits from 196 well-characterized DHF/DSS subjects.

Elevated IL-12 serum level has been reported in DF patients and not in DHF/DSS patients [44, 45]. Two polymorphisms within the IL-12B gene, IL-12Bpro and IL-12B 3'UTR Taq I polymorphism, were shown to influence IL-12p70 synthesis and may be functionally relevant in disease with an altered Th1 balance $[22,23,46-48]$. We showed here that the combined genotypes IL-12Bpro homozygote/TNF- $\alpha$ $-308 \mathrm{GA}+\mathrm{AA}$ and IL-12B 3UTR AC/TNF- $\alpha$ -308GA+AA were significantly associated with protective effects against DHF/DSS. The presence of the $C$ allele in IL-12B $3^{\prime}$ UTR is associated with higher production of IL-12 [23, 24, 49] and the C allele has also been related to spontaneous viral clearance in Hepatitis C infection [50]. On the other hand, the IL-12Bpro homozygosity has been associated with a higher gene transcription and cytokine production than the IL-12Bpro heterozygote [22, 47, 51, 52] and the low expressing IL-12Bpro heterozygous confers risk to cerebral malaria $(\mathrm{CM})$ [51]. The functional effect of the IL12B gene polymorphisms in response to DENV infection, however, requires further investigation.

Earlier studies showed that increased production of IL-10 in DHF patients was accompanied with suppressed secretion of IL-12 and TNF- $\alpha$, impaired T cell proliferation and altered antiviral IFN response [53]. And the presence of IL-10 promoter -1082G allele is associated with higher levels of IL-10 production [54]. Studies in Venezuela and Cuba populations, however, reported contradicting results that the low IL-10 production-related ACC/ATA haplotypes was associated with DHF [38, 39]. No significant differences in the frequency of IL-10 gene variants between the DF and DHF/DSS patients and control group were noted in our study. The combination of low IL-10 producing non-GCC haplotypes and TNF- $\alpha-308 \mathrm{GA}+\mathrm{AA}$ genotypes, however, was significantly correlated with protective effects against development of DHF/DSS. This finding supports the previous findings that high IL-10 production is associated with severe dengue [12, $15,16]$. It is envisage that naturally high production of
IL-10, genetically regulated during the early phase of infection could result in unrestricted virus replication. This would lead to increase number of infected cells and tissues with subsequent over-production of inflammatory mediators which could then trigger vascular leakages $[55,56]$. Incidentally, high virus load and prolonged viremia have been correlated with increased dengue severity $[57,58]$.

Our finding that possession of high TNF- $\alpha /$ low IL-10 genotypes is protective against thrombocytopenia and elevated AST is in agreement with previous reports that high serum level of IL-10 is associated with thrombocytopenia and raised liver enzymes in dengue patients $[55,59,60]$. At this point, however, there is no direct clinical or physiological role of TNF- $\alpha$ and IL-12 in the pathogenesis of thrombocytopenia or liver damage seen in the severe dengue apart from indirectly stimulating immune responses to reduce virus load hence reducing infection of the bone marrow and liver.

The current study is a retrospective case-control study. Lack of serial clinical and laboratory data of the dengue patients is among the limitations of the study. A prospective study is desired to enable investigation of the functional relationship between host genetics and the dynamics of virus load and host immune response at the early stage of DENV infection. These analyses, however, have been limited and are almost impossible as the dengue patients did not present to the medical centers until they developed symptoms and became sick. Biological data is needed to verify the functionality of gene polymorphisms with actual cytokine production during infection. These data would be useful for further understanding of the physiological relevance of the gene polymorphisms in the pathogenesis of DHF/DSS vis-à-vis protection against severe dengue. In the present study, we did not pursue this further due to the limitation of sample size especially for those gene alleles or genotypes which are rare in our population [61].

In conclusion, our study reports an association of the high producing TNF- $\alpha$ alleles and genotypes with protection against development of DHF/DSS. Combination of TNF- $\alpha-308 \mathrm{GA}+\mathrm{AA}$ genotypes and IL-10 non-GCC haplotypes, IL-12Bpro homozygotes and IL-12B 3'UTR AC are associated with protective effects against DHF/DSS. Our study also revealed a protective association between the genotypes and clinical features significant in DHF/DSS, which included thrombocytopenia and elevated liver enzymes. Efficient viral clearance at the early stage of infection in an environment of low IL-10 and high TNF- $\alpha$ could be the mechanism conferring protection against manifestation of severe dengue. Further evaluation, however, is needed to investigate the 
possibility of early treatment with TNF- $\alpha$ or anti-IL-10 antibody for the prevention against severe outcome of dengue.

\section{Abbreviations}

DENV: Dengue virus; DF: dengue fever; DHF: dengue hemorrhagic fever; DSS: dengue shock syndrome; IL: interleukin; UTR: untranslated region; ADE: antibody-dependent enhancement; Th: T helper; TNF- $\alpha$ : tumor necrosis factor-alpha; NO: nitric oxide; IFN- $\gamma$ : interferon-gamma; UMMC: University Malaya Medical Center; IRB: institutional review board; WHO: World Health Organization; SNP: single nucleotide polymorphism; PCR: polymerase chain reaction; RFLP: restriction fragment length polymorphism; DPO: dual priming oligonucleotide; OR: odds ratio; CI: confidence interval; AST: aspartate aminotransferase; ALT: alanine aminotransferase; LTA: lymphotoxin alpha.

\section{Acknowledgements}

We thank the Ministry of Science, Technology, and Innovation of Malaysia for Malaysia Genome Institute initiative grant 07-05-MGI-GMB015, the Ministry of Higher Education, Malaysia for LRGS grant (LRGS/TD/2011/UM/Penyakit-Berjangkit), and University of Malaya for Postgraduate Research Fund (PS148/2008C and PS408/2010A).

\section{Conflict of Interest}

The authors have declared that no competing interest exist.

\section{References}

1. Gubler DJ. The economic burden of dengue. Am J Trop Med Hyg. 2012; 86: 743-744

2. WHO. Dengue hemorrhagic fever: diagnosis, treatment, prevention and control. 2nd ed. Geneva, Switzerland: World Health Organization; 1997.

3. Sam SS, Omar SF, Teoh BT, et al. Review of Dengue hemorrhagic fever fatal cases seen among adults: a retrospective study. PLoS Negl Trop Dis. 2013; 7: e2194.

4. [Internet] CDC: USA. Epidemiology. Revised 28 October 2013. http://www.cdc.gov/dengue/epidemiology/

5. Watts DM, Porter KR, Putvatana P, et al. Failure of secondary infection with American genotype dengue 2 to cause dengue haemorrhagic fever. Lancet. 1999; 354: 1431-1434.

6. Halstead SB. Neutralization and antibody-dependent enhancement of dengue viruses. Adv Virus Res. 2003; 60: 421-467.

7. Mongkolsapaya J, Dejnirattisai $\mathrm{W}, \mathrm{Xu} \mathrm{XN}$, et al. Original antigenic sin and apoptosis in the pathogenesis of dengue hemorrhagic fever. Nat Med. 2003; 9 : 921-927.

8. Pang T, Cardosa MJ, Guzman MG. Of cascades and perfect storms: the immunopathogenesis of dengue haemorrhagic fever-dengue shock syndrome (DHF/DSS). Immunol Cell Biol. 2007; 85: 43-45.

9. Fried JR, Gibbons RV, Kalayanarooj S, et al. Serotype-specific differences in the risk of dengue hemorrhagic fever: an analysis of data collected in Bangkok, Thailand from 1994 to 2006. PLoS Negl Trop Dis. 2010; 4: e617.

10. Halstead SB. Pathogenesis: risk factors prior to infection. In: Halstead SB, editor. Dengue. London: Imperial College Press; 2008: 219-256.

11. Mustafa AS, Elbishbishi EA, Agarwal R, et al. Elevated levels of interleukin-13 and IL-18 in patients with dengue hemorrhagic fever. FEMS Immunol Med Microbiol. 2001; 30: 229-233.

12. Perez $A B$, Garcia $G$, Sierra $B$, et al. IL-10 levels in Dengue patients: some findings from the exceptional epidemiological conditions in Cuba. J Med Virol. 2004; 73: 230-234
13. Raghupathy R, Chaturvedi UC, Al-Sayer H, et al. Elevated levels of IL-8 in dengue hemorrhagic fever. J Med Virol. 1998; 56: 280-285.

14. Restrepo BN, Isaza DM, Salazar CL, et al. Serum levels of interleukin-6, tumor necrosis factor-alpha and interferon-gamma in infants with and without dengue. Rev Soc Bras Med Trop. 2008; 41: 6-10.

15. Chareonsirisuthigul T, Kalayanarooj S, Ubol S. Dengue virus (DENV) antibody-dependent enhancement of infection upregulates the production of anti-inflammatory cytokines, but suppresses anti-DENV free radical and pro-inflammatory cytokine production, in THP-1 cells. J Gen Virol. 2007; 88: 365-375.

16. Ubol S, Phuklia W, Kalayanarooj S, et al. Mechanisms of immune evasion induced by a complex of dengue virus and preexisting enhancing antibodies. J Infect Dis. 2012; 201: 923-935.

17. Sun P, Bauza K, Pal S, et al. Infection and activation of human peripheral blood monocytes by dengue viruses through the mechanism of antibody-dependent enhancement. Virology. 2011; 421: 245-252.

18. Chapman SJ, Hill AV. Human genetic susceptibility to infectious disease. Nat Rev Genet. 2012; 13: 175-188.

19. Kaluza W, Reuss E, Grossmann S, et al. Different transcriptional activity and in vitro TNF-alpha production in psoriasis patients carrying the TNF-alpha 238A promoter polymorphism. J Invest Dermatol. 2000; 114: 1180-1183.

20. Kroeger KM, Carville KS, Abraham LJ. The -308 tumor necrosis factor-alpha promoter polymorphism effects transcription. Mol Immunol. 1997; 34: 391-399.

21. Mueller T, Mas-Marques A, Sarrazin C, et al. Influence of interleukin 12B (IL12B) polymorphisms on spontaneous and treatment-induced recovery from hepatitis C virus infection. J Hepatol. 2004; 41: 652-658.

22. Peng JC, Abu Bakar S, Richardson MM, et al. IL10 and IL12B polymorphisms each influence IL-12p70 secretion by dendritic cells in response to LPS. Immunol Cell Biol. 2006; 84: 227-232.

23. Seegers D, Zwiers A, Strober W, et al. A TaqI polymorphism in the 3'UTR of the IL-12 p40 gene correlates with increased IL-12 secretion. Genes Immun. 2002; 3: 419-423.

24. Stanilova S, Miteva L. Taq-I polymorphism in 3'UTR of the IL-12B and association with IL-12p40 production from human PBMC. Genes Immun. 2005; 6: 364-366.

25. Wilson AG, Symons JA, McDowell TL, et al. Effects of a polymorphism in the human tumor necrosis factor alpha promoter on transcriptional activation. Proc Natl Acad Sci U S A. 1997; 94: 3195-3199.

26. Edwards-Smith CJ, Jonsson JR, Purdie DM, et al. Interleukin-10 promoter polymorphism predicts initial response of chronic hepatitis $\mathrm{C}$ to interferon alfa. Hepatology. 1999; 30: 526-530.

27. Davoodi-Semiromi A, Yang JJ, She JX. IL-12p40 is associated with type 1 diabetes in Caucasian-American families. Diabetes. 2002; 51: 2334-2336.

28. Chun JY, Kim KJ, Hwang IT, et al. Dual priming oligonucleotide system for the multiplex detection of respiratory viruses and SNP genotyping of CYP2C19 gene. Nucleic Acids Res. 2007; 35: e40.

29. Green S, Vaughn DW, Kalayanarooj S, et al. Early immune activation in acute dengue illness is related to development of plasma leakage and disease severity. J Infect Dis. 1999; 179: 755-762.

30. Hober D, Poli L, Roblin B, et al. Serum levels of tumor necrosis factor-alpha (TNF-alpha), interleukin-6 (IL-6), and interleukin-1 beta (IL-1 beta) in dengue-infected patients. Am J Trop Med Hyg. 1993; 48: 324-331.

31. Shi YJ, Jiang ZY, Zeng K. [Effect of IL-6 and TNF-alpha on Dengue virus infection of human dendritic cells]. Xi Bao Yu Fen Zi Mian Yi Xue Za Zhi. 2006; 22: 469-471.

32. Burke DS, Nisalak A, Johnson DE, et al. A prospective study of dengue infections in Bangkok. Am J Trop Med Hyg. 1988; 38: 172-180.

33. Endy TP, Chunsuttiwat S, Nisalak A, et al. Epidemiology of inapparent and symptomatic acute dengue virus infection: a prospective study of primary school children in Kamphaeng Phet, Thailand. Am J Epidemiol. 2002; 156: 40-51.

34. Shrestha B, Zhang B, Purtha WE, et al. Tumor necrosis factor alpha protects against lethal West Nile virus infection by promoting trafficking of mononuclear leukocytes into the central nervous system. J Virol. 2008. 82. 8956-8964.

35. Wada H, Saito K, Kanda T, et al. Tumor necrosis factor-alpha (TNF-alpha) plays a protective role in acute viralmyocarditis in mice: A study using mice lacking TNF-alpha. Circulation. 2001; 103: 743-749.

36. Kim YJ, Lee HS, Yoon JH, et al. Association of TNF-alpha promoter polymorphisms with the clearance of hepatitis B virus infection. Hum Mol Genet. 2003; 12 : 2541-2546.

37. Seo SH, Webster RG. Tumor necrosis factor alpha exerts powerful anti-influenza virus effects in lung epithelial cells. J Virol. 2002; 76: 1071-1076.

38. Fernandez-Mestre MT, Gendzekhadze K, Rivas-Vetencourt $\mathrm{P}$, et al. TNF-alpha-308A allele, a possible severity risk factor of hemorrhagic manifestation in dengue fever patients. Tissue Antigens. 2004; 64: 469-472.

39. Perez AB, Sierra B, Garcia G, et al. Tumor necrosis factor-alpha, transforming growth factor-beta1, and interleukin-10 gene polymorphisms: implication in protection or susceptibility to dengue hemorrhagic fever. Hum Immunol. 2010; 71: 1135-1140.

40. Loke H, Bethell D, Phuong CX, et al. Susceptibility to dengue hemorrhagic fever in vietnam: evidence of an association with variation in the vitamin $\mathrm{d}$ receptor and Fc gamma receptor IIa genes. Am J Trop Med Hyg. 2002; 67: 102-106 
41. Garcia-Trejo AR, Falcon-Lezama JA, Juarez-Palma L, et al. Tumor necrosis factor alpha promoter polymorphisms in Mexican patients with dengue fever. Acta Trop. 2011; 120: 67-71.

42. Vejbaesya S, Luangtrakool P, Luangtrakool K, et al. TNF and LTA gene, allele, and extended HLA haplotype associations with severe dengue virus infection in ethnic Thais. J Infect Dis. 2009; 199: 1442-1448.

43. Moreira ST, Cardosa DM, Visentainer JE, et al. The possible protective role of the IL6-174 GC genotype in dengue fever. The Open Tropical Medicine Journal. 2008; 1: 87-91.

44. Chaturvedi UC, Raghupathy R, Pacsa AS, et al. Shift from a Th1-type response to Th2-type in dengue haemorrhagic fever. Curr Sci. 1999; 76: 63-69.

45. Pacsa AS, Agarwal R, Elbishbishi EA, et al. Role of interleukin-12 in patients with dengue hemorrhagic fever. FEMS Immunol Med Microbiol. 2000; 28: 151-155.

46. Morahan G, Boutlis CS, Huang D, et al. A promoter polymorphism in the gene encoding interleukin-12 p40 (IL12B) is associated with mortality from cerebral malaria and with reduced nitric oxide production. Genes Immun. 2002; 3: 414-418.

47. Morahan G, Huang D, Wu M, et al. Association of IL12B promoter polymorphism with severity of atopic and non-atopic asthma in children. Lancet. 2002; 360: 455-459.

48. Morahan G, Huang D, Ymer SI, et al. Linkage disequilibrium of a type 1 diabetes susceptibility locus with a regulatory IL12B allele. Nat Genet. 2001; 27: 218-221.

49. Bergholdt R, Ghandil P, Johannesen J, et al. Genetic and functional evaluation of an interleukin-12 polymorphism (IDDM18) in families with type 1 diabetes. J Med Genet. 2004; 41: e39.

50. Houldsworth A, Metzner M, Rossol S, et al. Polymorphisms in the IL-12B gene and outcome of HCV infection. J Interferon Cytokine Res. 2005; 25: 271-276.

51. Marquet S, Doumbo O, Cabantous S, et al. A functional promoter variant in IL12B predisposes to cerebral malaria. Hum Mol Genet. 2008; 17: 2190-2195.

52. Muller-Berghaus J, Kern K, Paschen A, et al. Deficient IL-12p70 secretion by dendritic cells based on IL12B promoter genotype. Genes Immun. 2004; 5: 431-434.

53. Ubol S, Masrinoul P, Chaijaruwanich J, et al. Differences in global gene expression in peripheral blood mononuclear cells indicate a significant role of the innate responses in progression of dengue fever but not dengue hemorrhagic fever. J Infect Dis. 2008; 197: 1459-1467.

54. Turner DM, Williams DM, Sankaran D, et al. An investigation of polymorphism in the interleukin-10 gene promoter. Eur J Immunogenet. 1997; 24: 1-8.

55. Nguyen TH, Lei HY, Nguyen TL, et al. Dengue hemorrhagic fever in infants: a study of clinical and cytokine profiles. J Infect Dis. 2004; 189: 221-232.

56. Morens DM, Halstead SB. Measurement of antibody-dependent infection enhancement of four dengue virus serotypes by monoclonal and polyclonal antibodies. J Gen Virol. 1990; 71: 2909-2914.

57. Wang WK, Chen HL, Yang CF, et al. Slower rates of clearance of viral load and virus-containing immune complexes in patients with dengue hemorrhagic fever. Clin Infect Dis. 2006; 43: 1023-1030.

58. Vaughn DW, Green S, Kalayanarooj S, et al. Dengue viremia titer, antibody response pattern, and virus serotype correlate with disease severity. J Infect Dis. 2000; $181: 2-9$

59. Azeredo EL, Zagne SM, Santiago MA, et al. Characterisation of lymphocyte response and cytokine patterns in patients with dengue fever. Immunobiology. 2001; 204: 494-507.

60. Libraty DH, Endy TP, Houng HS, et al. Differing influences of virus burden and immune activation on disease severity in secondary dengue-3 virus infections. J Infect Dis. 2002; 185: 1213-1221.

61. Sam SS, Teoh BT, AbuBakar S. The IL-10 and IL-12B gene polymorphisms in the multiethnic Malaysian population. Genet Mol Res; in press. 